Document downloaded from:

http://hdl.handle.net/10251/110351

This paper must be cited as:

Cobacho Jordán, R.; Arregui De La Cruz, F.; Cabrera Marcet, E.; Cabrera Rochera, E. (2008). Private Water Storage Tanks: Evaluating Their Inefficiencies. Water Practice \& Technology. 3(1):1-8. doi:10.2166/wpt.2008.025

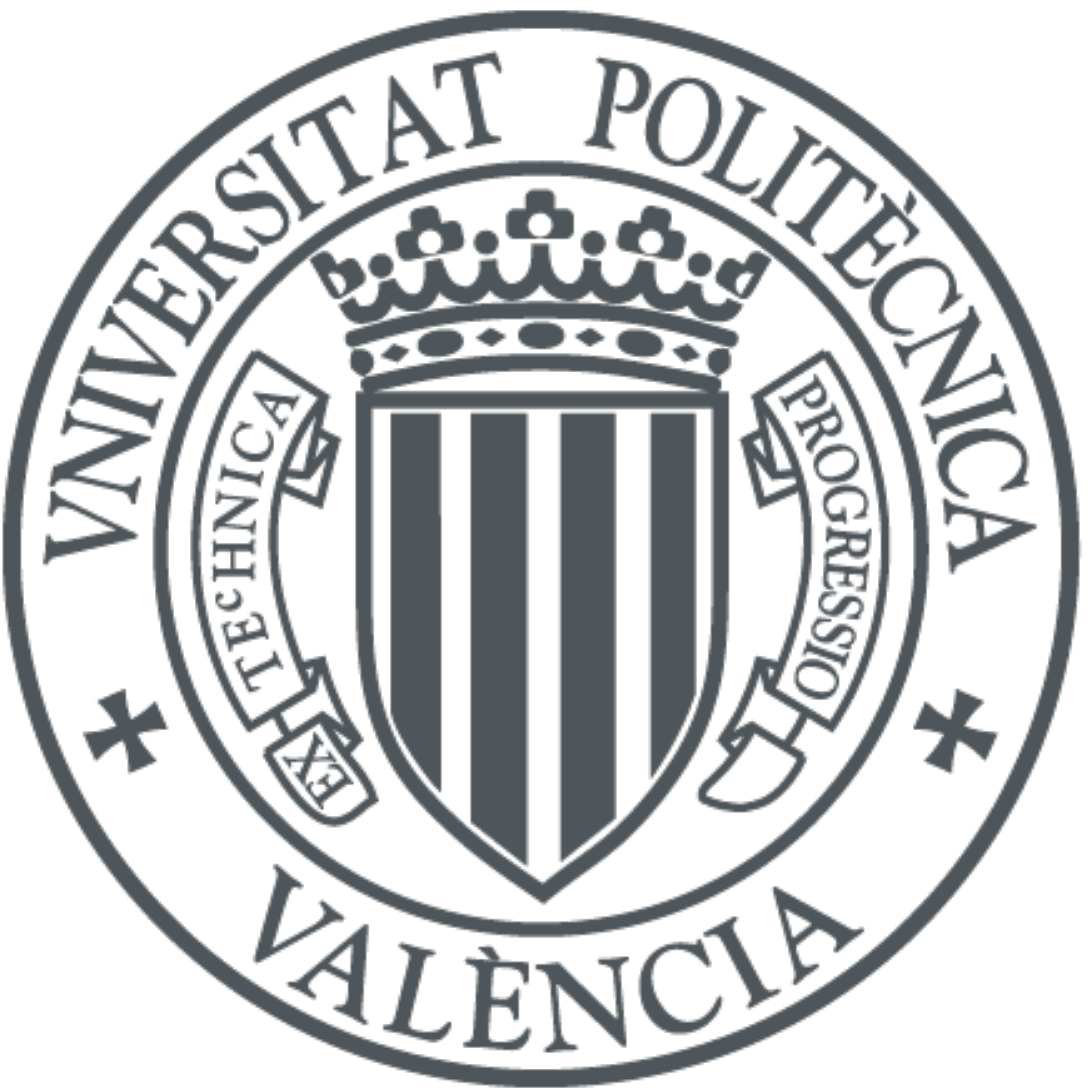

The final publication is available at

https://doi.org/10.2166/wpt.2008.025

Copyright IWA Publishing

Additional Information 


\title{
PRIVATE WATER STORAGE TANKS: EVALUATING THEIR INEFFICIENCIES
}

\author{
Ricardo Cobacho; Francisco Arregui, Enrique Cabrera, Enrique Cabrera Jr. \\ Institute for Water Technology. Polytechnic University of Valencia. Spain. \\ rcobacho@ita.upv.es; farregui@ita.upv.es; ecabrera@ita.upv.es; qcabrera@ita.upv.es \\ Fax number: +34963879899
}

Keywords: Private storage tanks, water meter, error, water leakage, ufw

\begin{abstract}
Private water storage tanks are often considered as very inefficient devices than can only be justified in systems that suffer frequent water service interruptions. This paper presents the results obtained after studying four different aspects of this question: the effect of this kind of tanks on water losses, unaccounted for water, time modulation curve and energy losses (other implications, such as those related to water quality deterioration, remain out of the scope of the study). Conclusions for each particular point will turn uneven, specially highlighting the effect on the meter global error and unregistered water. In any case, all four points, as well as several additional issues to be considered, are described and evaluated.
\end{abstract}

\section{Introduction: the problem}

Scarcity and irregularity are both traditional attributes of water resources all along the Mediterranean Coast of Spain, which is longer than $2000 \mathrm{~km}$ and hosts an average population of 17 million people (nearly $40 \%$ of total Spanish population).

Because of this fact, nearly every single family house and multiapartment building is equipped with a private storage water tank. Either located on the roof or beneath the ground, the aim of this tank is to provide a temporary water storage capacity for daily consumption. In this way, the tank tries to compensate possible service interruptions. The need and use of private tanks is so deeply assumed that even the new standards about building construction (MV, 2006) provides guidelines for proper sizing.

However, there exists some doubts about possible negative effects this kind of tanks could present (Arregui et al., 2006; ITA, 2006). In short:

1. Waste of water (real losses)? Faulty operation of these tanks seems to be usual, and so significant leaks could appear in float valve or joints. Furthermore, in most cases this waste would be unnoticed for the user and the utility, since leaking flowrates come below the meter starting flowrate.

2. Waste of economic efficiency (apparent losses)? Even in the case of no leakage, the use of these tanks decreases the flowrates entering the tank from the network pipes. These diminished flowrates cold reach the high error zone of the meter error curve and hence, the volume of unaccounted for water could become significantly increased.

3. Waste of management range for network managers? From a different view, the use of these tanks 'flattens' and 'deforms' the pattern of water demand curve, thus becoming an obstacle to distinguish different kind of losses within the water balance. 
4. Waste of energy? Releasing the pipe water into a tank before consuming it means losing (and wasting) the pipe pressure. New energy is then needed to pressurize it again to reach end uses.

5. Waste of water quality? Once pipe water enters the tank, it remains at rest in contact with open air. In case the main water source of the system is surface water with a high load of organic compounds, long remaining times of water in private storage tanks could give rise to THM to appear.

Currently, a debate is open about these tanks: need versus wasting. A widely spread feeling considers that water systems relying on these tanks are those defective, that thus try to hide their defective operating conditions. Conversely, in efficient systems, private tanks would become useless and wasting elements to be avoided. To provide some results on this issue, authors are developing some studies on a small size utility (16,500 households). In this case, storage tanks classify into two types: the ones located onto the roof of every single family house and those ones located in the basement of multiapartment buildings, of common use for all the flats of the building. After a first stage, this paper presents the main findings of the work for the 4 former points above mentioned (quality issues, at the moment, come out of the study goals).

\section{Tank effect on the volume inefficiency: the study}

Although just finished for the case of single family houses, this former point has turned out to be the most important one. Volume inefficiencies are originated by both the water use pattern and the meter error curve, and the way to evaluate them has relayed on a direct water use monitoring in a number of households. Due to the high number of factors that could affect both variables, any kind of simulation process was not advisable (what was in the end confirmed by results). A sample compounded by 46 households was selected taking into account the following features:

- Similar size $\left(90 \mathrm{~m}^{2}\right)$ and occupancy (3 to 4 people).

- Similar age (15 to 20 years).

- Similar storage tank size (1000 litres), tank location (on the roof) and water meter location (just upstream from the tank).

The influence of the storage tank was evaluated by obtaining the water consumption pattern. Thus, by means of accurate new meters such patterns were obtained for each household. Unlike it had been expected (bearing the even features of the households), the variability of different water use patterns was very high. After analysis, the reason for it was found to be the existing different degrees of tank by-pass (Figure 1):

- A household with an indoor piping installation that fully by-passes the storage tank (

- Figure 4) allows users to take water directly from the service connection pipe, thus remaining the tank as a secondary storage device with no frequent use. Average flowrates use to be quite high and both the water use pattern and water use profile look very similar to those corresponding to an ideal reference household with no tank.

- A piping installation with a partially by-passed tank (Figure 3) allows users to take water consumption from two sources: the service connection pipe (short steep uses) and the storage tank (long flat uses).

- A piping installation with a not by-passed tank (Figure 2), only allows users to take water from the tank, thus producing very long and flat uses with high volume. 
Figure 1. Different water use patterns depending on the tank by-pass
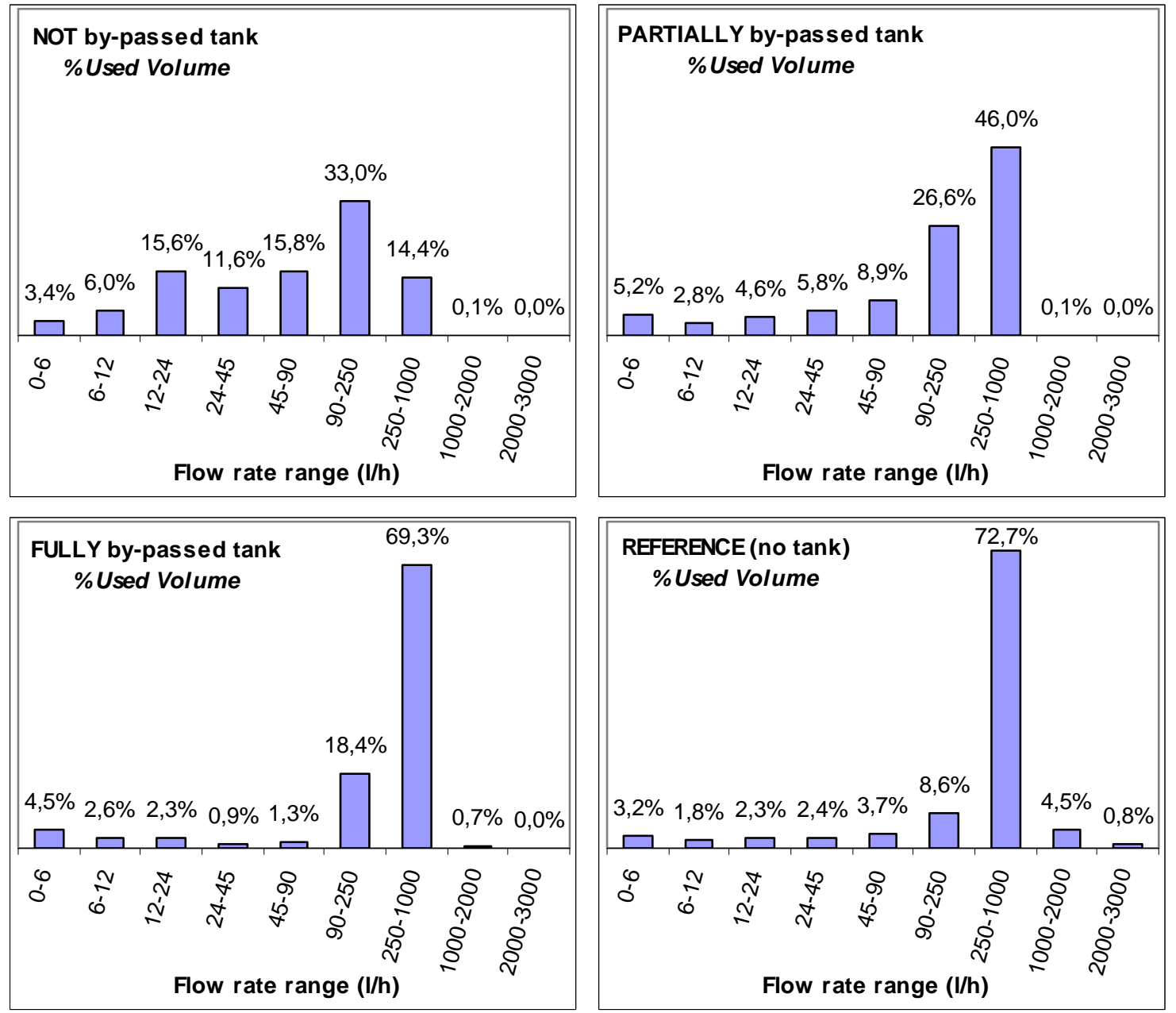

Figure 2. Water use profile in case of a NOT by-passed tank

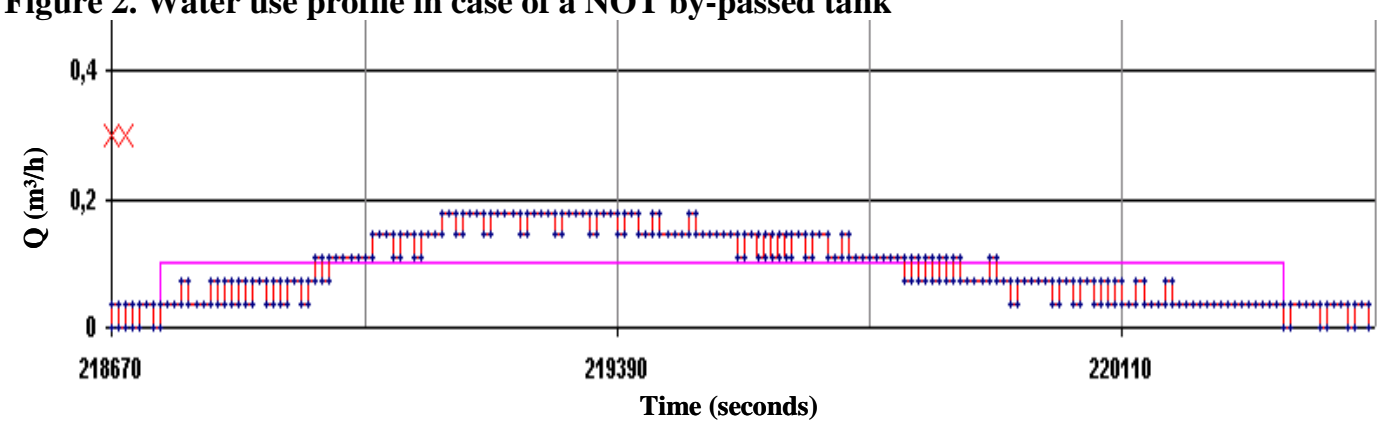

As we can see from the water use profiles, the effect of the tank becomes critical in flattening the average flowrates. Unlike other works (Cobacho et al., 2005), in these circumstances it is not possible to distinguish leakage from consumption only attending to the flowrate values (particularly, when the float valve is near to close). So, identification of real leaks has been performed by studying the regular frequency of some well-defined very low water use pulses. The figure thus obtained for it is, at least, about $5 \%$ of total household water demand. 
Figure 3. Water use profile in case of a PARTIALLY by-passed tank

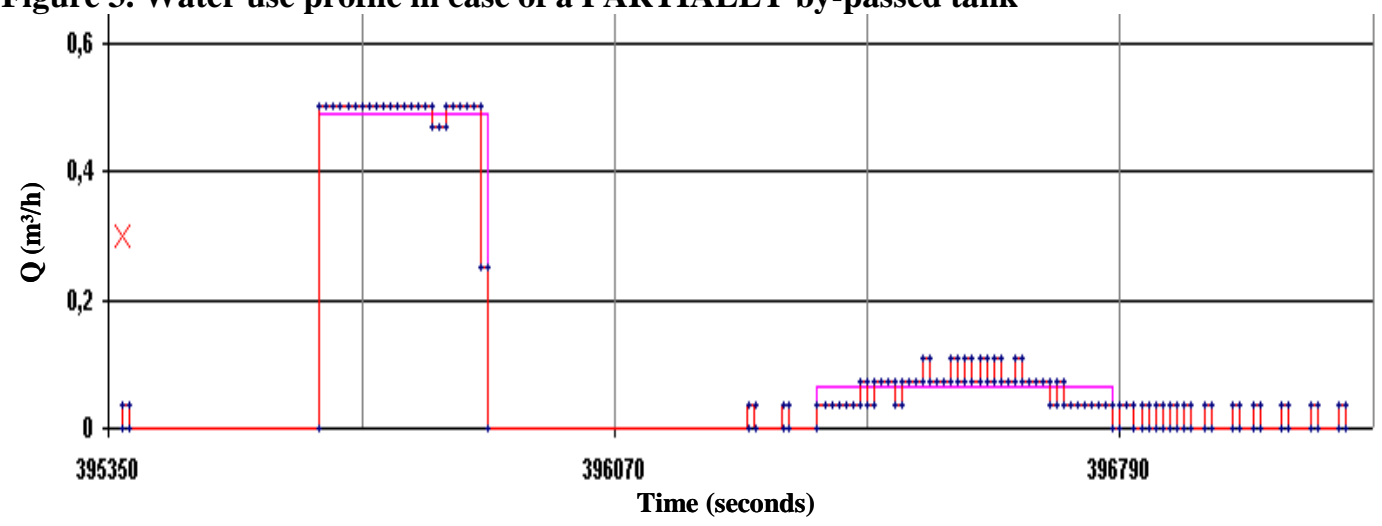

Figure 4. Water use profile in case of a FULLY by-passed tank

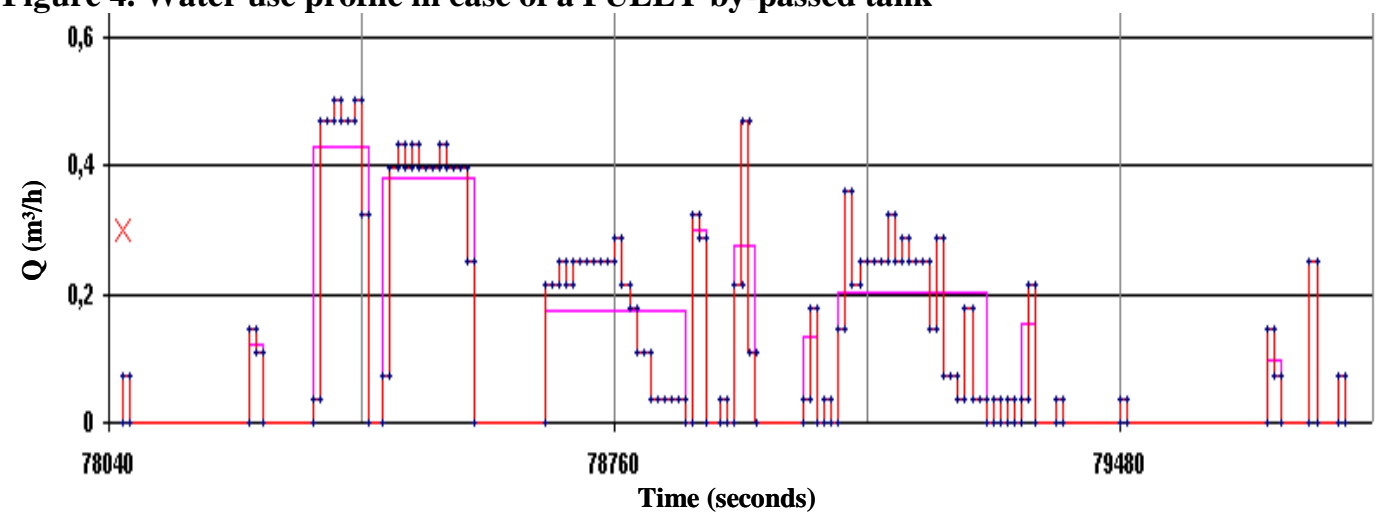

\section{Tank effect on the volume inefficiency: the results}

The direct consequence of the different water use profiles and patterns is the different amounts of water that are subsequently unregistered by the meters. The error curve of a new Class B meter is accurate enough to keep the unregistered volume at low percentages. However, after some years the meter metrological conditions use to deteriorate and the unregistered volume could reach unacceptable figures. Figure 5 shows the degradation of a Class B meter.

Once the meter error curve and the water use patter are known, calculating the global error of a given meter is not difficult (Arregui et al., 2006), and performing such operations for all 3 different cases of tank by-passes found in our city and all 3 different meter age intervals, yields a really wide range of results for possible global meter errors (Figure 6 and table attached). 
Figure 5. Degradation of a Class B meter

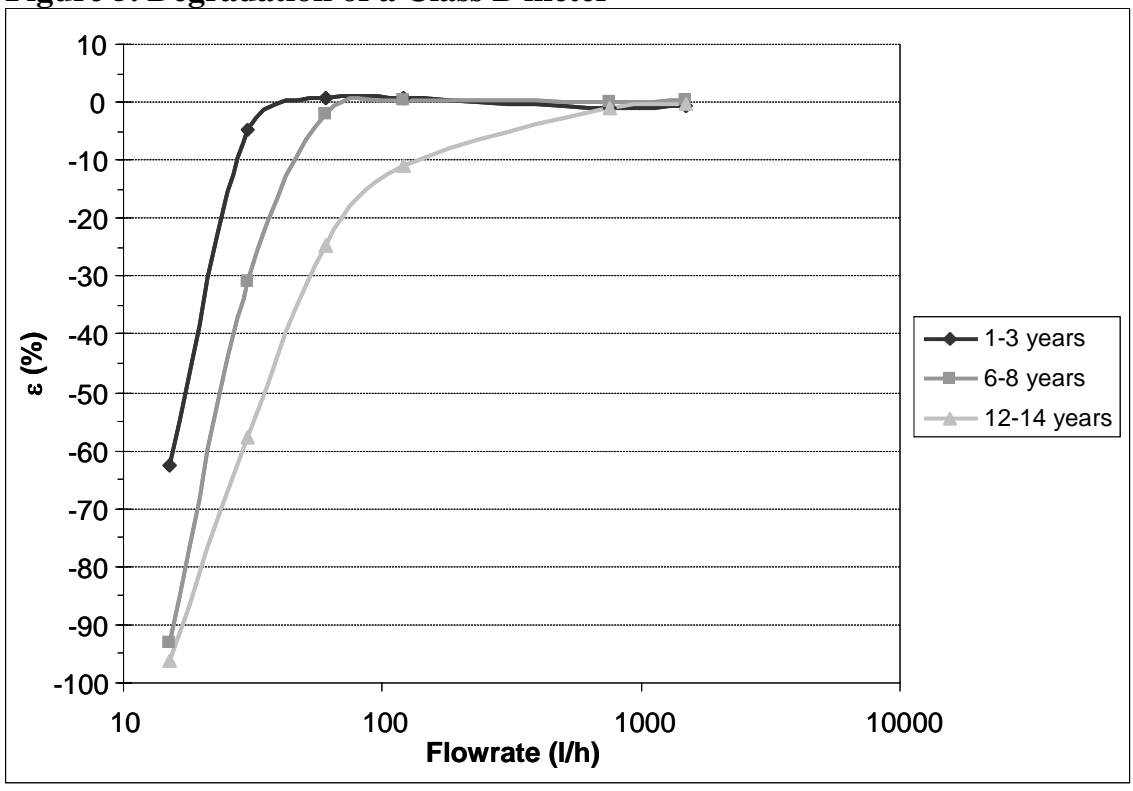

As shown, while the global error keeps on low figures for the fully by-passed configuration (which is not a surprise since that configuration nearly behaves in the same way of a direct intake configuration with no tank), in the case of a not by-passed configuration the effect of the tank becomes very clear, increasing the global error close to the $-20 \%$ during the initial years, and to critical $-30 \%$ and worse from 6-8 years on.

Figure 6. Changes on global meter error depending on meter age for different tank configurations

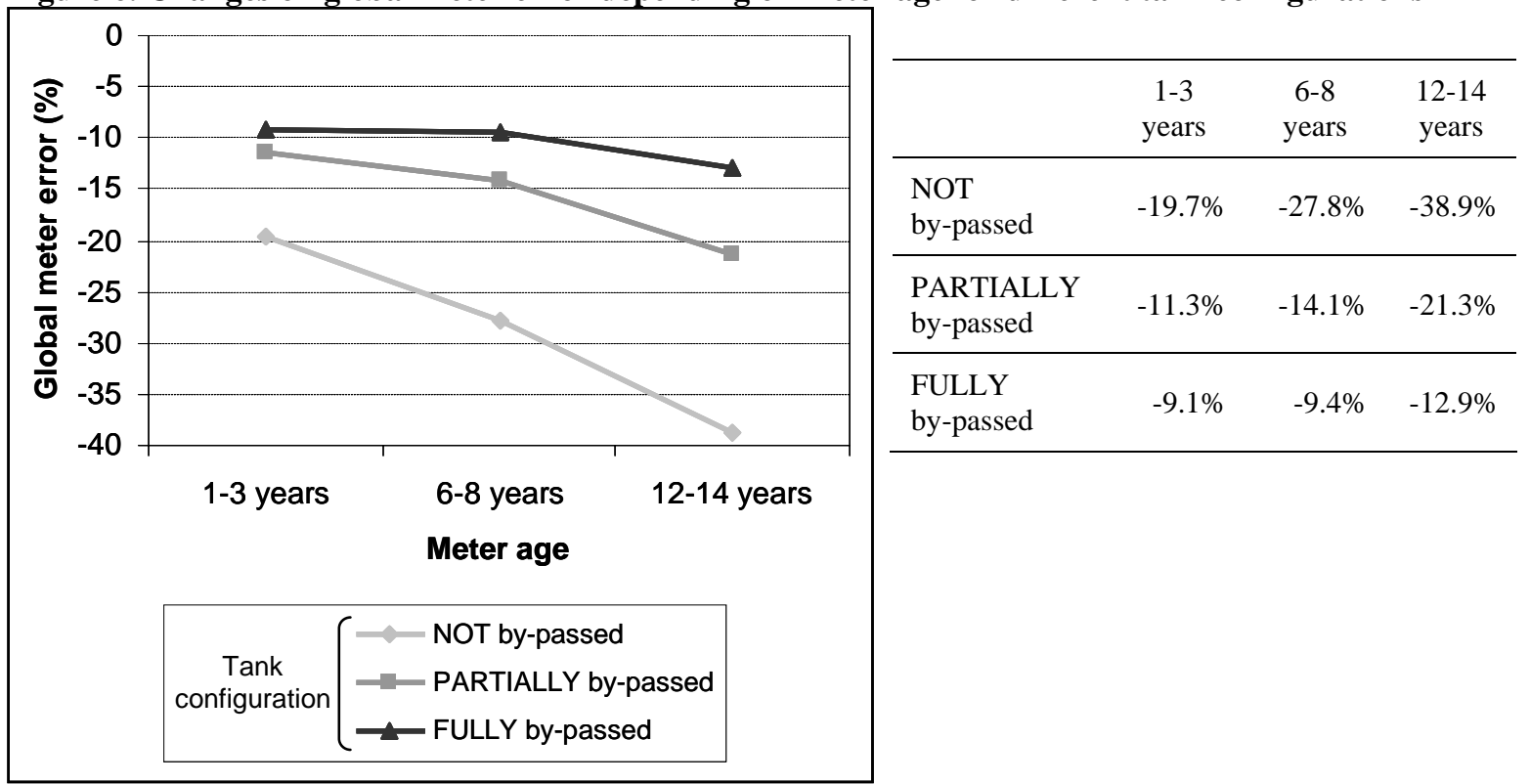

These results try to show the high uncertainties behind the use of private storage tanks. With possible changes greater than $100 \%$ (from $-9 \%$ to $-20 \%$, in the best case), their contribution to the global meter error makes them a critical factor for the total unaccounted for water in the utility. 


\section{Tank effect on the time modulation curve of water consumption}

Results obtained in this point do not really offer clear conclusions. Compared to the strong effect of the (not by-passed) tank in consumption flowrates just presented, its influence in the time modulation of consumption is much more modest. The size of the tank does flatten the water use profile, but not to the extent of changing remarkably the time modulation curve. This type of curve has been obtained for single family houses with a not-by passed tank (Figure 7, left) and also for houses with a fully by-passed tank (Figure 7 , right), none special difference seems to appear between them.

Figure 7. Time modulation curves for water consumption (left: not by-passed, right: fully by-passed)

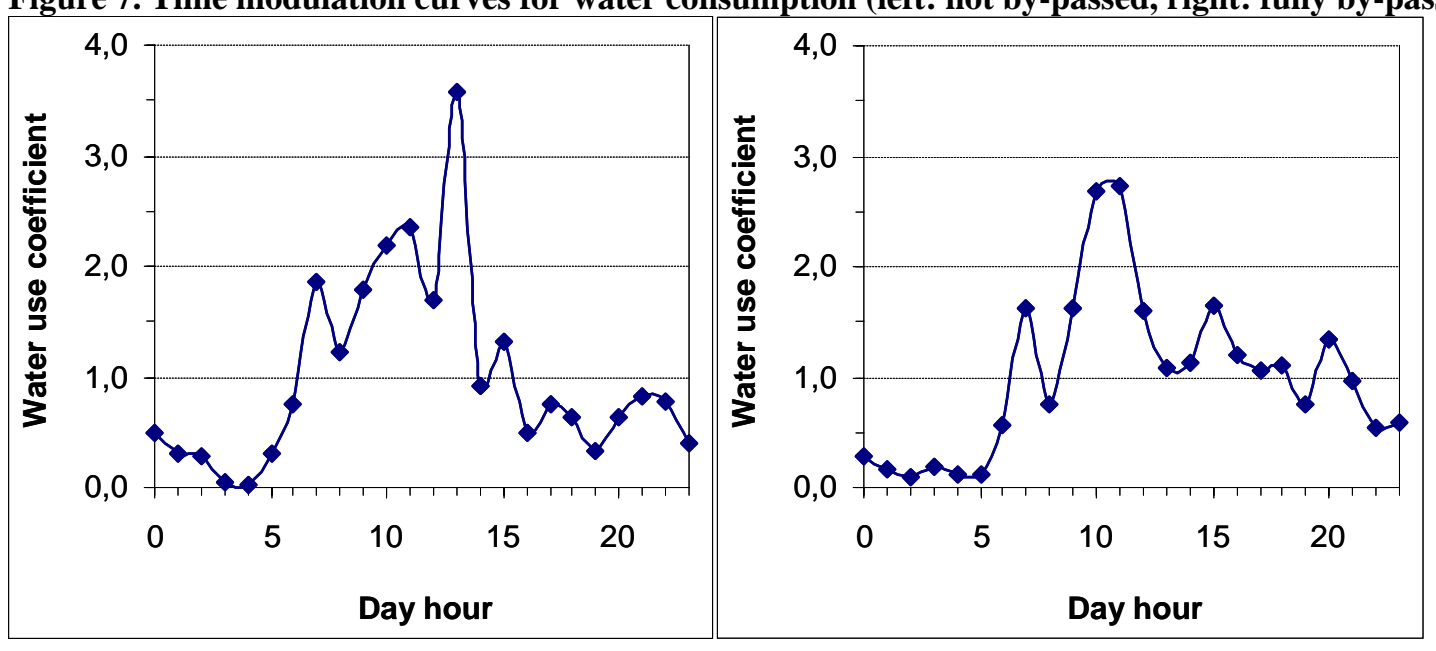

In fact, we can expect results like these since water uses through a tank become flatter (Figure 2 and Figure 3), but mostly within a lapse of minutes, hardly longer than one hour. That effect, very relevant for the average flowrate values, gets dissolved into the 1-hour time modulation curve. Possibly, results will be different for the case of community storage tanks in multi apartment buildings, to be tackled in a next stage of the work.

\section{Tank effect on the energy inefficiency}

Assessing an initial estimate of the energy inefficiencies due to the use of private storage water tanks is not too complicate, since it is based principally on the average water consumption and the average service pressure. According to Spanish standards the available pressure at service connection should be $15 \mathrm{~m}$ higher than the building being supplied. This means that, in general terms, pressure levels in a city should be about $20 \mathrm{~m}$ pressure in areas with low buildings (ground and first floor), and about $30 \mathrm{~m}$ pressure, and more, in areas with high buildings (ground and 6 floors).

As water enters the storage tank, all pipe pressure is immediately released. To make end uses possible, water needs to be re-pressurised again to some extent, and it is achieved by means of the simple gravity in single family houses with the tank located on the roof, or by another second pumping system in buildings, in which the communal use tank is located in the basement. In both cases, a real pressure loss takes place, which means a real amount of wasted energy, and it can be estimated by comparing the final available pressure in households with tank to that available in direct connection households: 
- For single family houses, since the tank is on the roof and end uses are supplied by gravity, pressure loss could be, in average, about $\Delta P=8$ (m/house), which yields $\Delta E=6.3(\mathrm{kWh} /$ house/year), taking $500 \mathrm{l} /$ day as average water use and 0.65 as pumping efficiency.

- For multiapartment buildings, in the best case, lower floors have a direct service connection, whereas upper floors are supplied through the tank and a pump. The energy loss is then originated when having to re-pump again the service pressure value for these upper floors, i.e. $\Delta P=H-(H-h)=h$ (m/building). Being: $H$ total pressure needed to the highest floor, and $h$ network service pressure. The final amount of energy loss per apartment turns out $\Delta E=26.3(\mathrm{kWh} /$ apartment in an upper floor/year), also taking $500 \mathrm{l} /$ day as average water use and 0.65 as pumping efficiency.

In the undiserable (worst) case of not having a direct connection for lower floors and being all apartments supplied through the tank and the pump, resulting figures become higher, as shown by

Figure 8: numerical values for energy loss per apartment under above mentioned conditions (500 l/day water use, 0.65 pumping efficiency, $27 \mathrm{~m}$ service network pressure) either for only upper apartments or all apartments being supplied through the tank and the pump.

Figure 8. Pressure loss per flat in multiapartment buildings with storage tank in the basement

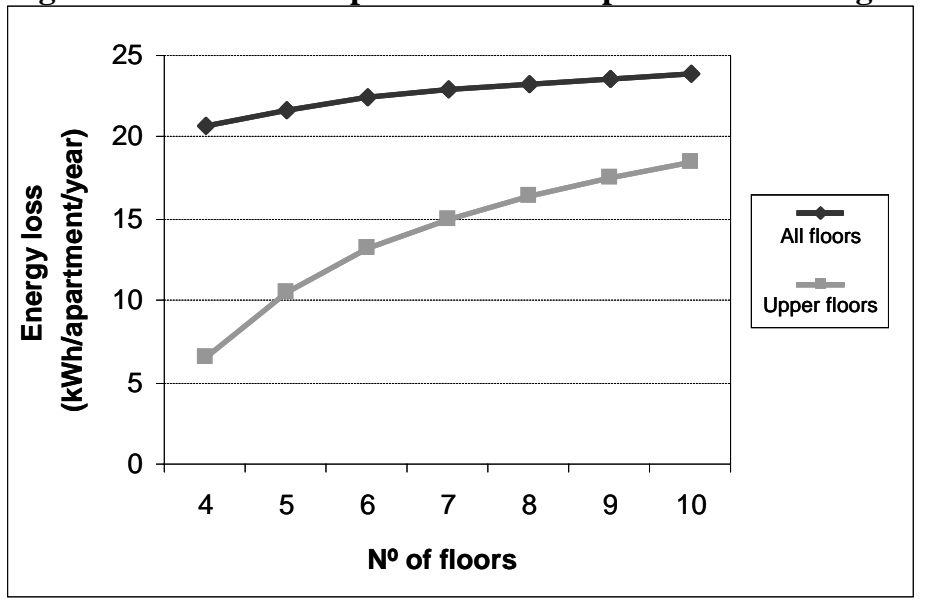

\begin{tabular}{rrr}
\hline \multirow{2}{*}{$\begin{array}{c}\mathrm{N}^{\circ} \text { of } \\
\text { floors }\end{array}$} & \multicolumn{2}{c}{$\begin{array}{c}\text { Energy loss } \\
\text { (kWh/apartment/year) }\end{array}$} \\
\cline { 2 - 3 } & All floors & $\begin{array}{c}\text { Just upper } \\
\text { floors }\end{array}$ \\
\hline 4 & 20.6 & 6.6 \\
\hline 5 & 21.7 & 10.5 \\
\hline 6 & 22.4 & 13.2 \\
\hline 7 & 22.9 & 15.0 \\
\hline 8 & 23.3 & 16.4 \\
\hline 9 & 23.6 & 17.5 \\
\hline 10 & 23.8 & 18.4 \\
\hline
\end{tabular}

In principle, these are not impressive figures. Actually, this loss -which becomes essential to provide an adequate water service-, is not faced by the utility but by the final user himself; and should it be compared to the rest of household expenses and shared with the rest of the building neighbours, it will probably be unnoticed. However, it is doubtlessly a real loss caused by the bad condition of the system (service interruptions or insufficient network pressure). A holistic analysis, from the whole Society's perspective, is needed since the necessary infrastructure works to improve the network, while equally shared among all users, could be not far from this unnoticed 'tax' (authors' experience on a similar issue can be found at Dubois \& Cabrera, 2004). 


\section{Conclusions}

Concerning four initial questions about possible inefficiencies caused by private water storage tanks in cities, this paper has presented the results obtained in a pilot study developed on a small Mediterranean city. Taking yet into account the particular features of households, meters and water consumptions, results like these can also be expected in other countries. Conclusions for each question are summarised next:

- The increase of unaccounted for water due to tank operation has turned out to be the most relevant result. The effect of the tank on consumption flowrates could rise the global error of the user's meter, in the best case, from an acceptable -9\% (non operational or fully by-passed tank) to a critical $-20 \%$ (for fully operational or not by-passed tank). These figures will yet become worse as the meter ages, finding global errors up to $-40 \%$ for fully operational tanks with 14 years-old meters.

- The tank decreases water use flowrates so much that water losses due to tank or valve leakage get hidden within unaccounted for water. An analysis of monitoring provides a least figure of 5\% for such losses, but they are probably higher.

- In single family houses, flat consumptions due to tank operation do extend in time but hardly longer than one hour, so it is not really noticed on the hourly modulation consumption curve. Tank effect on apartment buildings will probably be stronger.

- Finally, an analysis of the energy loss due to tank operation yields figures of 4.2 and $7.3 \mathrm{kWh} /$ year for houses and apartments, respectively. In this case particular attention has been paid when considering network service pressure conditions, number of floors in a building and average water consumption.

\section{Acknowledgments}

Authors would like to thank the essential support of SPANISH MINISTRY OF EDUCATION, through the research project "Ordenación y valoración de estrategias orientadas ala progresiva eliminación de los depósitos de almacenamiento de los usuarios en los abastecimientos de agua urbanos”. CGL2005-03666/HID.

\section{References}

Arregui, F.; Cabrera Jr., E.; Cobacho, R. 2006. Integrated water meter management. Arregui, F.; Cabrera, E. Jr.; Cobacho, R. IWA Publishing.

Cobacho, R.; Arregui, F.; Parra J.C.; Cabrera Jr. E. Improving efficiency in water use and conservation in Spainsh hotels. Efficient 2005. Chile.

Dubois, M; Cabrera, E. Establecimiento del precio del agua a partir de los estándares de calidad de servicio. Trabajo de Investigación para la obtención del Diploma de Estudios Avanzados. Universidad Politécnica de Valencia. Spain

MV-Ministerio Vivienda. 2006. Código Técnico de la Edificación. Ministerio de Vivienda. Madrid. Spain.

ITA-Instituto Tecnológico del Agua. 2006. Control de las pérdidas de agua en sistemas de distribución de agua. Postgraduate course. Polytechnic University of Valencia. Spain. 